\title{
ELECTROCARDIOGRAPHIC CHANGES IN ATRIAL SEPTAL DEFECT FOLLOWING SURGICAL CORRECTION
}

\author{
BY \\ D. HYWEL DAVIES,* RAY PRYOR, AND S. GILBERT BLOUNT, Jr. \\ From the Department of Medicine, Cardiology Section, University of Colorado Medical Center, \\ Denver, Colorado, U.S.A. \\ Received July 15, 1959
}

The electrocardiogram in atrial septal defect is of great value, not only in the diagnosis but also in the assessment of the severity of the lesion. The pattern that has been designated "incomplete right bundle-branch block," though not present in every case nor by any means pathognomonic of the condition, is nevertheless frequently noted. Before describing the changes in the electrocardiogram following closure of the defect, we will discuss briefly the cardiogram before operation, the criteria of analysis, and the nomenclature that we use instead of incomplete right bundle-branch block. The material consists of 100 consecutive patients submitted to operation, ranging in age from ten months to 45 years. The surgical results have been fully reported elsewhere (Swan et al., 1959).

\section{FINDINGS BEFORE OPERATION}

The typical electrocardiogram of the secundum type of atrial septal defect shows sinus rhythm, though the incidence of atrial fibrillation rises with increasing age. In only 1 of the 100 patients, a 45-year-old woman, was sinus rhythm not present, the arrhythmia being atrial fibrillation. The $P$ wave tends to be pointed, and in 36 patients was more than $2.5 \mathrm{~mm}$. in height, giving an accuracy of just over one-third for this criterion of right atrial enlargement (Sokolow and Lyon, 1949), for at operation the right atrium was always considerably enlarged. The ratio of the $\mathbf{P}$ wave duration to the $P-R$ segment duration was less than 1.0 in all 36 of these patients. The $P-R$ interval was more than $0.2 \mathrm{sec}$. in four patients. The patients with the longer $P-R$ intervals were in the older age group.

Evaluation of the QRS complex offers the greatest aid in diagnosis. The QRS duration was $0.10 \mathrm{sec}$. or less in 87 patients, $0.11 \mathrm{sec}$. in 10 patients, $0.12 \mathrm{sec}$. in 2 patients, and $0.15 \mathrm{sec}$. in 1 patient. The mean QRS axis was usually vertical or rightward. True right axis deviation (more rightward than $+100^{\circ}$ on the triaxial reference system) was present in 81 per cent of the cases.

The terminal QRS vector points rightward and anteriorly, giving an $S$ in lead $I$, a terminal $R$ in AVR, a terminal $R^{\prime}$ in V3R and V1, and an S wave in V5 and V6. The QRS pattern in V1 may take several forms, and these are described as follows.

\section{QRS Patterns in V3R and VI}

(a) $r S r^{\prime}$ (Crista supraventricularis pattern). This pattern, shown in Fig. 1a, is a normal finding in children and occasionally in adults. In atrial septal defect it may be due to slight hypertrophy in the region of the crista supraventricularis, and is the expression of the mildest degree of derangement.

(b) $r S R^{\prime}$ (Fig. 1b) (Right ventricular outflow tract hypertrophy). This term is used instead of "incomplete right bundle-branch block" and the pattern is probably due to diastolic overloading

* Now Registrar, National Heart Hospital, London. 


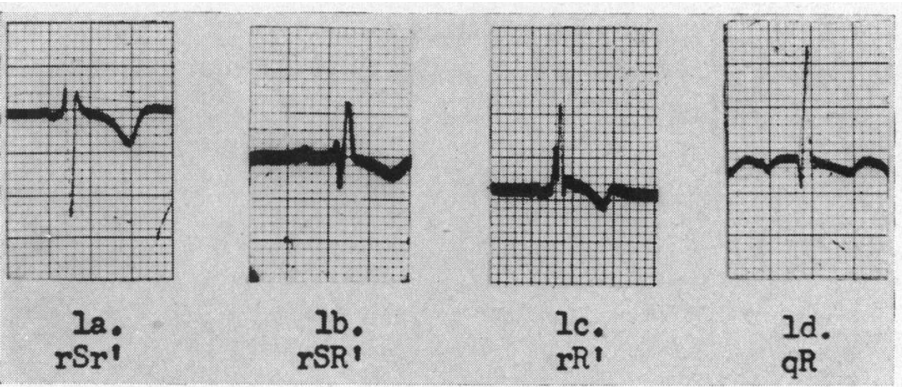

FIG. 1.-Four types of QRS complexes that may be seen in lead V1.

with dilatation of the right ventricle and especially dilatation and/or hypertrophy of the right ventricular outflow tract. This is the next stage, and is diagnosed when the $R^{\prime}$ exceeds $5 \mathrm{~mm}$. and is of greater magnitude than the $\mathrm{S}$ wave.

(c) $r R^{\prime}$ and $q R$ (Fig. $1 c$ and $1 d$ respectively). These are the patterns of right ventricular hypertrophy, each being expressive of a greater severity than (a) and (b). Occasionally a terminal $S$ wave may be noted. The height of the $\mathrm{R}^{\prime}$ in $\mathrm{V} 1$ is also helpful in evaluating the level of the pulmonary vascular resistance, though body build influences the actual magnitude of deflections recorded in the præcordial leads. A tall $\mathbf{R}^{\prime}$ in V3R or V1 usually implies a greater degree of right ventricular hypertrophy. It was pointed out by Wilson et al. (1947) that hypertrophy of the right ventricle combined with right bundle-branch block increased the height of the $\mathbf{R}^{\prime}$ in the right præcordial leads. Study of the patterns of regression after operation reveals that this is true in atrial septal defect.

The principles concerning the terminal vector abnormality that produces the various patterns seen in the right præcordial leads have been expounded (Blount et al., 1957), and constitute the basis for the evaluation of the pre-operative electrocardiograms of the 100 patients. The "crista pattern" was seen in 7 patients, the right ventricular outflow tract hypertrophy pattern (R.V.O.H.) in 65, and right ventricular hypertrophy (R.V.H.) in 28 patients.

Fig. 2 shows the relationship between the pulmonary arterial pressure and the patterns described above. There is an overlap between the groups, as would be expected when there is such a wide age range, but on the whole the incidence of the more severe right ventricular hypertrophy patterns increases as the pulmonary arterial pressure rises.

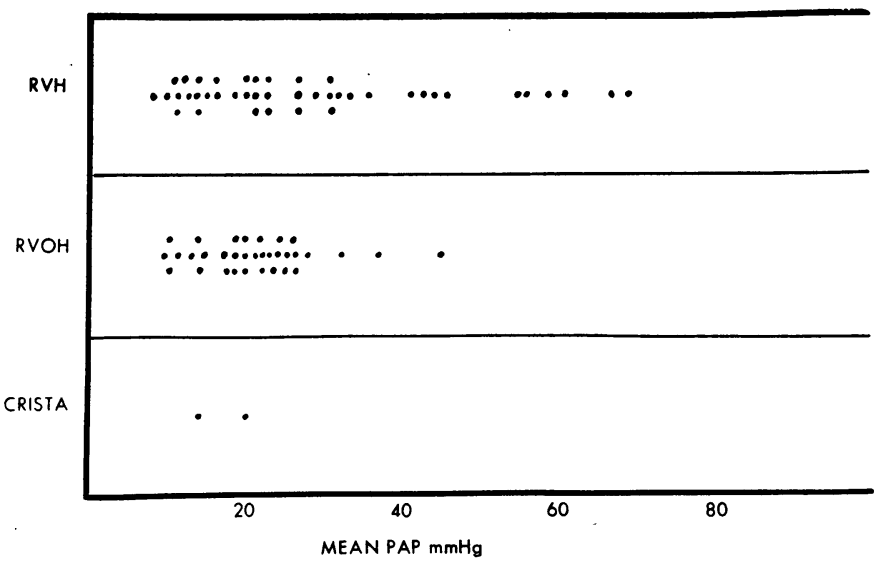

FIG. 2.-Relationship between electrocardiographic pattern and mean pulmonary arterial pressure. 
Fig. 3 shows the height of the $\mathrm{R}^{\prime}$ in $\mathrm{V} 1$ plotted against the mean pulmonary arterial pressure, and the same trend is noted. As shown in Fig. 4, this does not happen when the pulmonary artery blood flow is plotted against the height of the $\mathrm{R}^{\prime}$ in V3R or V1. This might be expected, since the expression for flow does not take into account the level of the pulmonary resistance. Since pressure is the product of flow and resistance, it would be expected to be related to the work of the right ventricle and hence the degree of hypertrophy.

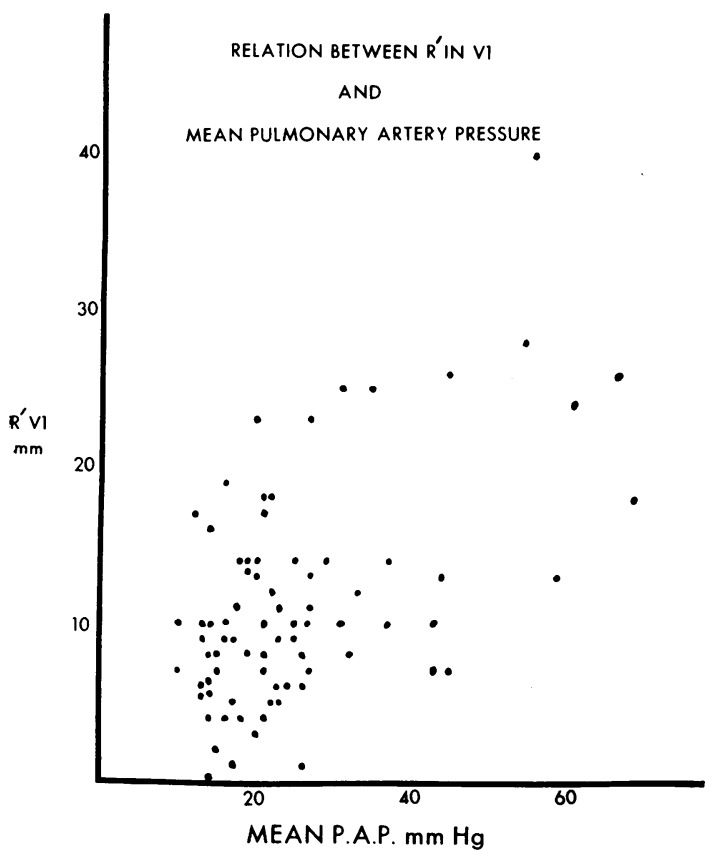

FIG. 3.-Relationship between the height of $R^{\prime}$ in V1 (in $\mathrm{mm}$.) and the mean pulmonary artery pressure.

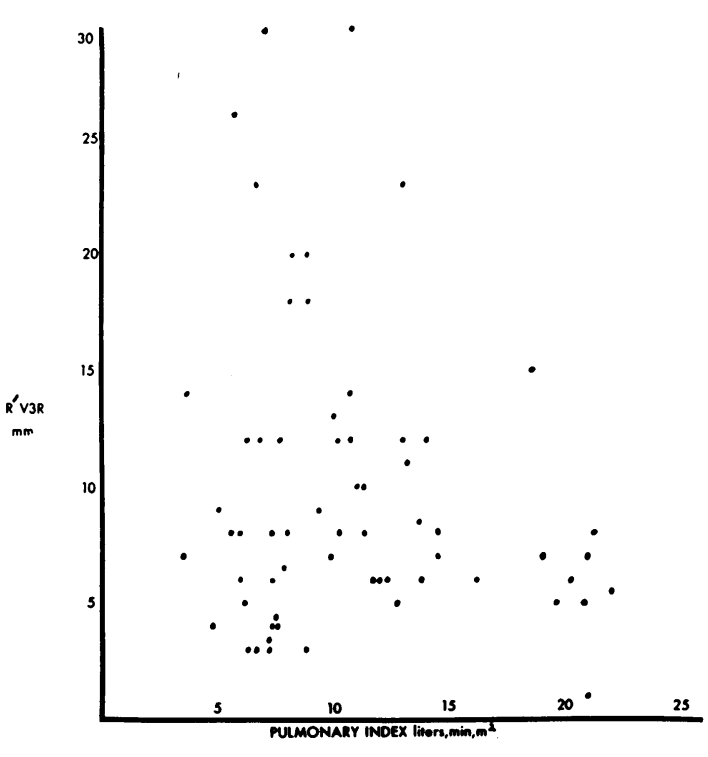

RELATION BETWEEN HEICHT OF $R^{\prime}$ in V3R AND PULMONARY HLW

FIG. 4.- Relationship between height of $R^{\prime}$ in V3R (in $\mathrm{mm}$.) and the pulmonary flow.

\section{ChANGES AFTER OPERATION}

Concomitant with the postoperative diminution in the size of the right atrium, the $P$ waves in most patients decrease in size. The $\mathbf{P}-\mathbf{R}$ interval also shortens in many patients. Atrial flutter appeared after operation in 6 patients, and proved permanent and refractory to therapy in three of these six. However, this complication leads to difficulties only if the ventricular rate is inadequately controlled. Atrial fibrillation is a common accompaniment of hypothermia and disappeared in all patients after re-warming.

QRS Complex. The most significant postoperative changes are in the QRS complex. The mean electrical axis moves towards the left. The $S$ wave in lead I diminishes, as does the $R$ in AVR, the $R^{\prime}$ in V3R and V1, and the S in V5 and V6.

Fig. 6 illustrates three of the types of QRS complexes that are described above. The uppermost is the $r R^{\prime}$ pattern with the $R^{\prime}$ measuring $16 \mathrm{~mm}$. The middle complex was recorded one week after operation and shows the rs $\mathrm{R}^{\prime}$ pattern. The lower complex, taken six months later, shows the $\mathrm{rSr}^{\prime}$ pattern. These complexes represent a regression in the degree of right ventricular hypertrophy or dilatation occurring following surgery.

It must not be assumed, however, that such a rapid change is usual after operation. The electrocardiograms shown in Fig. 6 are exceptional in this respect. The tracing taken a few days after operation not infrequently shows a temporary increase in the height of the $\mathrm{R}^{\prime}$ in V3R or V1, particularly if there are pulmonary complications. Within two months, however, definite changes are 
observed and then further regression may be noted for years after operation. Fig. 5 illustrates a typical sequence. Note that the mean QRS axis rotates leftward (true right axis deviation changes to a normal axis) and the $\mathrm{rSR}^{\prime}$ regresses to $\mathrm{rSr}^{\prime}$ in lead $\mathrm{V} 3 \mathrm{R}$.

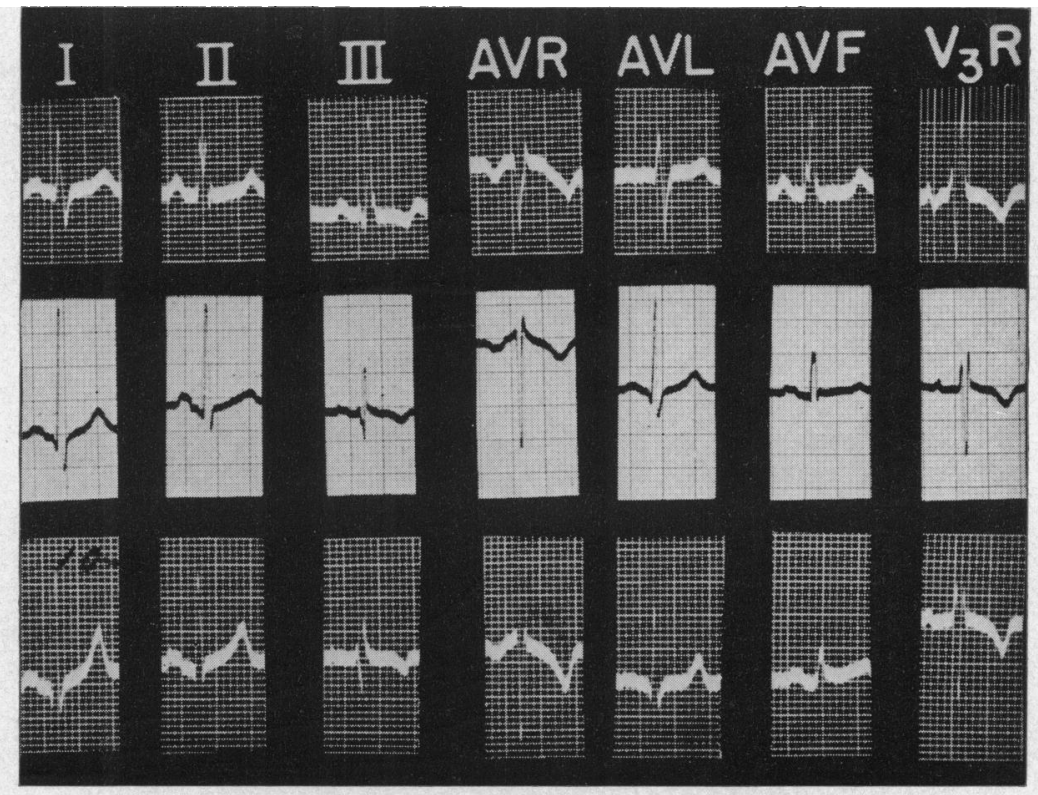

Fig. 5.-The normal pattern of regression after closure of an atrial septal defect.

Above: on $3 / 11 / 54$, two days before operation.

In middle: on 26/4/56, eighteen months after.

Below: on 24/10/56, nearly two years after.

In Fig. 8 it can be noted that the wide QRS complex of pre-operative complete right bundlebranch block has persisted, although it is apparent that the height of the $\mathrm{R}^{\prime}$ has decreased. In this series the two patients with complete right bundle-branch block before operation showed no change in this conduction defect following successful closure of the defect, despite manifest improvement in all other respects.

It is apparent that the most constant and significant post-operative change is the decrease in voltage in the $R^{\prime}$ in V1. Fig. 9 is a graph in which the amplitude of the $R^{\prime}$ in V1 before operation is plotted against the amplitude after it. In the rectangle to the left, the height of the $R^{\prime}$ in $V 1$ is recorded in 91 patients before operation. The general fall in the height of the $R^{\prime}$ in $V 1$ is readily apparent. When this method is applied to individual patients, the values of the $R^{\prime}$ in $V 1$ are found to lie on remarkably smooth curves, as illustrated in Fig. 7. The lower curves show the usual fall, and it is seen that the changes are most rapid during the first six months after operation, and thereafter become more gradual. The two upper curves will be discussed later.

\section{Discussion}

It is again emphasized that the $\mathrm{rSR}^{\prime}$ pattern seen in V3R and V1 is probably due to dilatation and/or hypertrophy of the right ventricular outflow tract rather than any interruption of conduction in the right bundle branch. Thus, the term right ventricular outflow tract hypertrophy is considered more appropriate than the term incomplete right bundle-branch block that has been used so frequently in the past.

Following successful closure of the atrial septal defect, the diastolic overloading of the right ventricle is removed. Right ventricular dilatation is diminished and there is regression of the right 

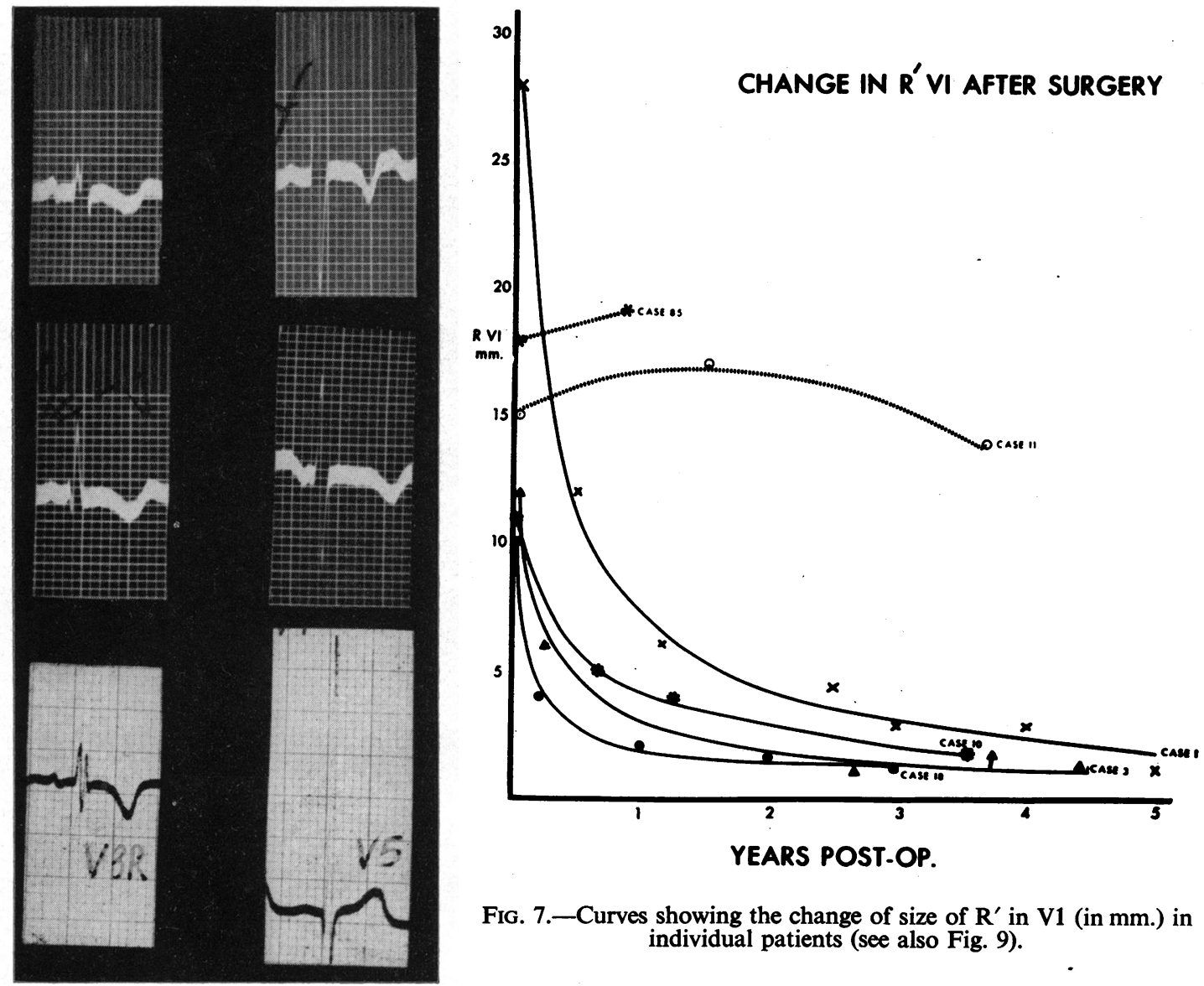

FIG. 7.-Curves showing the change of size of $R^{\prime}$ in V1 (in $\mathrm{mm}$.) in individual patients (see also Fig. 9).

FIG. 6.- Rather quick regression of right ventricular hypertrophy. The transition from one stage to the next is well seen.

Above: (2/12/54) shows the "right ventricular hypertrophy" pattern in V.3R. Operation was on 9/12/54.

In middle: $(16 / 12 / 54)$ the "right ventricular outflow tract hypertrophy" pattern.

Below: (27/6/55) the "crista" pattern.

ventricular outflow tract hypertrophy. Because of these changes the $R^{\prime}$ in $V 1$ decreases in magnitude and the mean QRS axis moves leftward:

It is not surprising that the postoperative changes should be graphically expressible by smooth curves, for at operation the abnormal hæmodynamic situation is suddenly corrected. The electrocardiogram is an accurate method, with the great merit of reproducibility, for the assessment of these changes.

When this cardiographic pattern of regression fails to occur, the reason must be explained. The upper two curves in Fig. 7 illustrate this point. The upper (Case 85) is plotted from the tracings of a patient who had severe pulmonary hypertension with a pressure in the pulmonary artery of 105/50 and a small left-to-right shunt before operation: following closure of the atrial septal defect the cardiogram failed to show the usual regression and recatheterization revealed that there was no longer a left-to-right shunt at atrial level, but that the pulmonary arterial pressure had not been lowered and was actually a little higher than before operation. The lower curve (Case 11) is plotted from the electrocardiograms of a 12-year-old boy who was entirely asymptomatic four years 


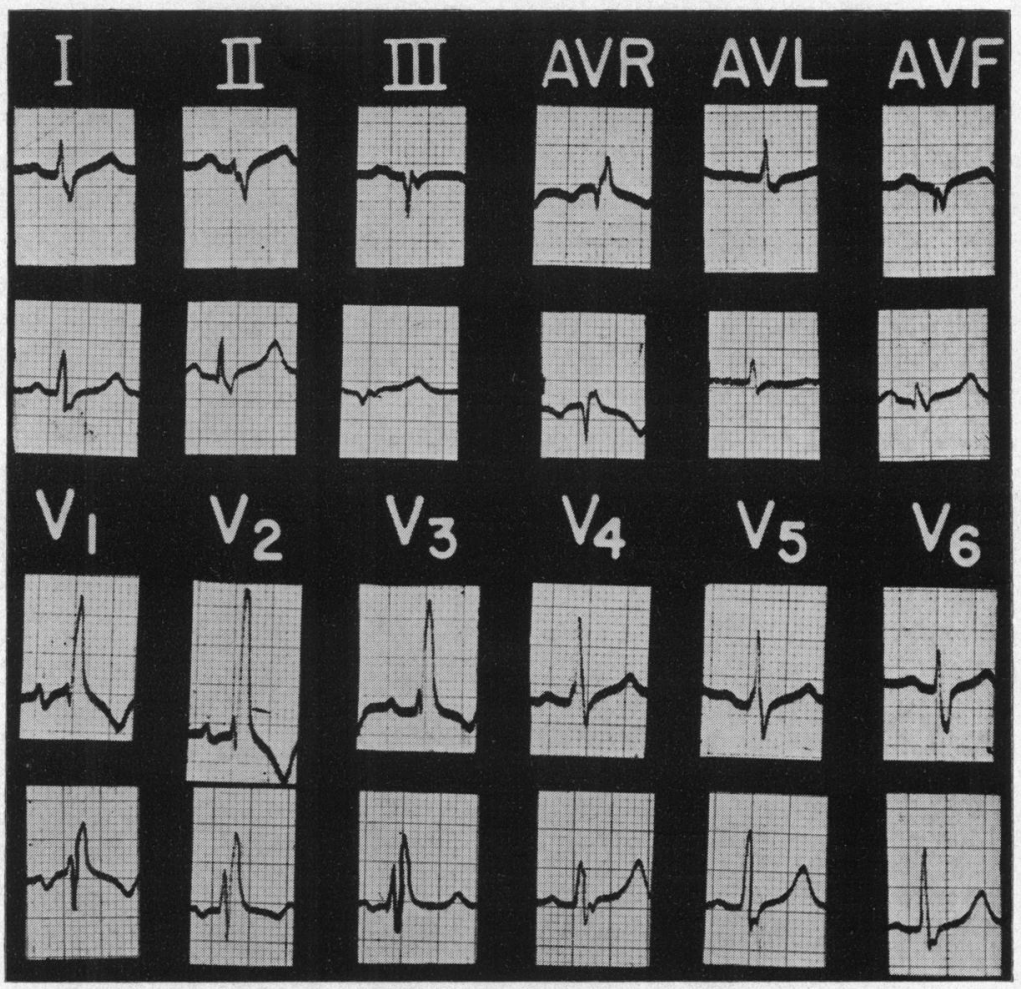

FIG. 8.-Electrocardiogram showing complete bundle-branch block before and after operation; but after operation $R^{\prime}$ in $V 1$ and $V 3$ has become much smaller. The upper sets of each pair were taken in 1955 two weeks after operation, and the lower sets 30 months later in 1958.

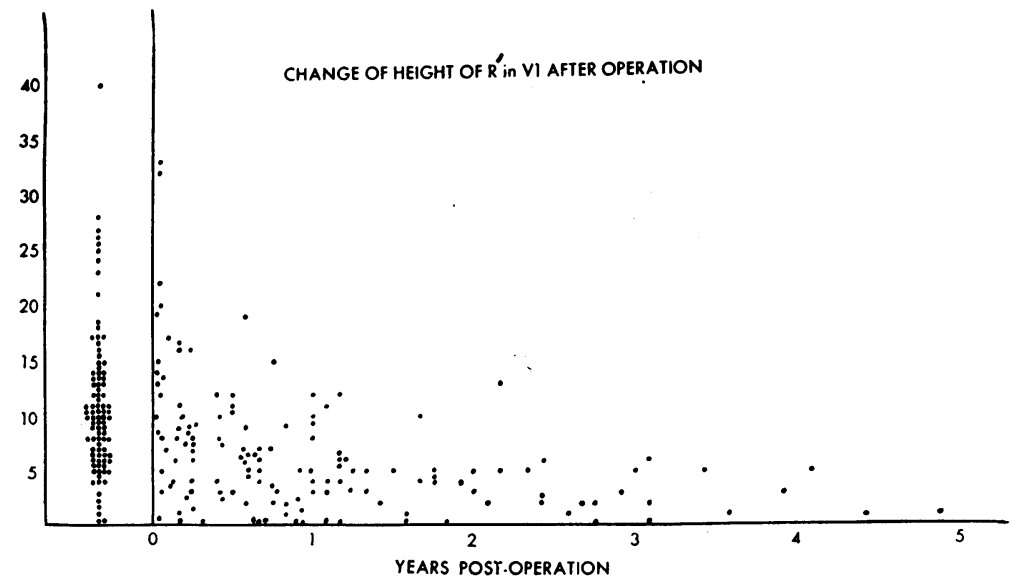

FIG. 9-In the rectangle to the left are the $R^{\prime}$ amplitudes (in $\mathrm{mm}$.) before operation, and to the right the $\mathbf{R}^{\prime}$ amplitudes so many years after operation. 
after operation. In the light of the failure of the cardiographic regression, he was brought back for re-examination, and clinical evaluation and cardiac catheterization revealed that the atrial defect was still open.

If this electrocardiographic regression is not obvious within four months after operation, in the absence of complicating factors, then the atrial septal defect is probably not completely closed. This regression occurred in all patients whose atrial septal defect was proved to be closed by clinical evaluation and cardiac catheterization. In all cases where regression did not occur, a good reason was found.

\section{SUMMARY}

The assessment of the electrocardiograms in atrial septal defects before and after operation is discussed.

The changes after operation are described. Diminution in the height of the $\mathbf{R}^{\prime}$ wave occurs in all successful cases, most rapidly in the first six months and more gradually thereafter. Changes may continue for at least five years after operation.

The rate at which regression takes place is described, and it is pointed out that the values for the $\mathbf{R}^{\prime}$ in V1 lie on a smooth curve.

If, in the absence of pulmonary complications, this regression is not apparent within four months after operation, it must be questioned whether the defect has, in fact, been closed.

\section{REFERENCES}

Blount, S. G., Jr., Munyan, A., and Hoffman, M. S. (1957). Amer. J. Med., 22, 784.

Swan, H., Kortz, A. B., Davies, H., and Blount, S. G., Jr. (1959). J. thorac. Surg., 37, 52.

Sokolow, M., and Lyon, F. (1949). Amer. Heart J., 38, 273.

Wilson, F. N., Rosenbaum, F. F., and Johnston, F. D. (1947). Advances intern. Med., 2, 1. 